\title{
ANALISIS STRATEGI PENGEMBANGAN USAHA PELAYANAN JASA ALAT DAN MESIN PERTANIAN (UPJA) DI KABUPATEN BOLAANG MONGONDOW TIMUR
}

\author{
Widjoyo Syuyono Mamonto \\ Richard E. M. F. Osak \\ Jolanda Kitsia Juliana Kalangi
}

\begin{tabular}{ll}
\hline Naskah diterima melalui Email agrisosioekonomi@unsrat.ac.id & : Selasa, 20 Oktober 2020 \\
Disetujui diterbitkan & : Minggu, 1 November 2020 \\
\hline
\end{tabular}

\begin{abstract}
This study aims to examine internal factors and external factors in developing a business in Alsintan Services (UPJA). And the formulation of strategy formulations in growing and developing business businesses in agricultural equipment services or UPJA. The research was conducted from July to August 2020. Located in three districts, namely Kotabunan District, Mooat District and Modayag District, Bolaang Mongondow Timur Regency. Sources of data in this study use primary and secondary data. Data analysis in this study uses the SWOT analysis method based on logic to be able to develop the maximum strength (strength) and opportunity (opportunity), but at the same time can also minimize weaknesses (weakness) and threats (threats). The results showed that the study of internal factors and external factors in the development of agricultural machine tool service business (UPJA), namely internal factors, namely the ability in company managerial and the experience of operators can be called strengths and also company administration in services to farmers and external factors of companies that participate in determining the direction of the development of agricultural equipment service businesses, namely government support, in this case the East Bolaang Mongondow Regency Agriculture Office and the potential for the availability of bank loans which are very supportive for the development of Agricultural Machine Tool Service Business Services (UPJA) as well as guarantee and ease of spare parts Then from the threat factor is the factor that gets attention, namely the low knowledge of farmers and farmers' capital for the use of alsintan. The formulation of the strategy for developing the Agricultural Machine Tool Service Business (UPJA) is an aggressive strategy or in quadrant I where the strategy used is all the strengths to take advantage of existing opportunities, as an alternative strategy to carry out socialization with the support of local governments through related agencies, fostering cooperation with farmers, increasing other agricultural business opportunities owned by UPJA, and increasing the availability of agricultural machinery.
\end{abstract}

Keywords: development, strategy formulation

\section{ABSTRAK}

Penelitian ini bertujuan untuk mengkaji faktor internal dan faktor eksternal dalam melakukan pengembangan suatu Usaha dalam Pelayanan Jasa Alsintan (UPJA). Dan untuk mengetahui perumusan formulasi strategi dalam menumbuh kembangkan bisnis usaha dalam pelayanan jasa alat pertanian atau UPJA. Penelitian dilaksanakan sejak bulan Juli sampai Agustus 2020. Berlokasi di Kabupaten Bolaang Mongondow Timur pada tiga kecamatan yaitu Kecamatan Kotabunan, Kecamatan Mooat dan Kecamatan Modayag. Sumber data dalam penelitian ini mengunakan data primer dan sekunder. Analisis data dalam penelitian ini menggunakan metode analis SWOT berdasar pada logika untuk dapat mengembangkan sebesar-besarnya kekuatan (strength) serta peluang (opportunity), tetapi secara bersamaan juga bisa meminimalisir kelemahan (weakness) serta ancaman (threat). Hasil penelitian menunjukkan bahwa kajian faktor internal dan faktor eksternal dalam pengembangan usaha pelayanan jasa alat mesin pertanian (UPJA) yaitu faktor internal yaitu kemampuan dalam manajerial perusahaan serta pengalaman dari operator bisa disebut sebagai kekuatan dan juga administrasi perusahaan dalam pelayanan kepada petani dan faktor eksternal perusahaan yang ikut dalam penentuan arah pengembangan usaha pelayanan jasa alat pertanian yaitu dukungan pemerintah dalam hal ini Dinas Pertanian Kabupaten Bolaang Mongondow Timur dan potensi tersedianya pinjaman bank yang sangat mendukung untuk pengembangan Usaha Pelayanan Jasa Alat Mesin Pertanian (UPJA) serta jaminan dan kemudahan suku cadang. Kemudian dari faktor ancaman adalah faktor yang mendapat perhatian yaitu rendahnya pengetahuan petani serta modal petani untuk penggunaan alsintan. Adapun formulasi strategi pengembangan Usaha Pelayanan Jasa Alat Mesin Pertanian (UPJA) yaitu strategi agresif atau pada kuadran I dimana strategi yang digunakan adalah semua kekuatan untuk memanfaatkan peluang yang ada, sebagai alternatif strategi melaksanakan sosialisasi dengan dukungan pemerintah daerah melalui dinas terkait, menumbuh kembangkan kerjasama dengan petani, peningkatan peluang usaha pertanian lain yang dimiliki UPJA, serta peningkatan ketersediaan alat mesin pertanian.

Kata kunci: pengembangan, formulasi strategi

Agrisosioekonomi:

Jurnal Transdisiplin Pertanian (Budidaya Tanaman, Perkebunan, Kehutanan, Peternakan, Perikanan), Sosial dan Ekonomi 


\section{PENDAHULUAN}

\section{Latar Belakang}

Alat dan mesin pertanian (alsintan) merupakan sarana yang tepat untuk meningkatkan kualitas dan kuantitas hasil pertanian, saat ini tidak hanya diproduksi oleh produsen besar baik di dalam maupun di luar negeri, namun juga sudah diproduksi oleh bengkel-bengkel pengrajin alsintan di seluruh tanah air. Alat, peralatan, dan mesin bertenaga adalah input yang penting dan utama untuk sarana pertanian dan bisa dianggap sebagai salah satu yang paling penting. Ada tiga sumber daya pertanian yang digunakan untuk alat dan mesin pertanian antara lain: rancangan manusia (manual) dengan menggunakan tenaga hewan dan tenaga bermotor.

Usaha Pelayanan Jasa Alat dan Mesin Pertanian merupakan lembaga yang bergerak di bidang ekonomi perdesaan yakni pada pelayanan jasa untuk optimalisasi dalam penggunaan alat alat serta mesin-mesin pertanian untuk memperoleh keuntungan usaha di dalam maupun diluar poktan dan gapoktan. Tumbuh kembang Usaha Pelayanan Jasa Alat Pertanian Secara umum di masyarakat.Kabupaten Bolaang Mongondow Timur sementara dikembangkan UPJA di setiap kecamatan. Saat ini sudah terdapat sebanyak 3 kelompok dengan klasifikasi UPJA Pemula yang mengelola masing-masing 1 unit Tractor roda 4, 6 tractor roda dua, 2 Power Thresher, 4 Pompa Air, 2 cultivator dan 10 Hand Sprayer elektrik (Dinas Pertanian Kabupaten Bolaang Mongondow Timur, 2019).

\section{Rumusan Masalah}

adalah

Rumusan masalah dalam penelitian ini

1. Bagaimana faktor internal serta faktor eksternal untuk melakukan pengembangan bisnis usaha dalam UPJA.

2. Bagaimanakah formulasi strategi dalam menumbuh kembangkan bisnis UPJA.

\section{Tujuan Penelitian}

Tujuan dalam penelitian ini adalah

a) Untuk mengkaji faktor dari internal serta faktor eksternal dalam melakukan pengembangan suatu usaha dalam pelayanan jasa alsintan atau UPJA.

b) Untuk perumusan formulasi strategi dalam menumbuh kembangkan bisnis usaha dalam pelayanan jasa alat pertanian atau UPJA.

\section{Manfaat Penelitian}

Manfaat dari penelitian ini adalah

1. Untuk pengelola usaha, yakni dengan dilakukannya penelitian ini, bagi masyarakat dan petani khususnya pengelola usaha dalam pelayanan jasa alat pertanian atau UPJA bisa menjadi acuan dalam pengembangan usahanya untuk peningkatan pendapatan.

2. Untuk peneliti yang lainnya, penelitian ini dapat menjadi dasar ilmu pengetahuan dan dapat pula menjadi acuan baru yang nantinya juga bisa membantu bagi peneliti yang lain ingin penelitian lebih lanjut tentang harapan kedepan dalam perkembangan usaha kecil untuk peningkatan ekonomi dalam usaha pelayanan jasa alsintan.

\section{METODE PENELITIAN}

\section{Waktu dan Lokasi Penelitian}

Penelitian dilaksanakan selama dua bulan dari bulan Juli sampai Agustus 2020. Berlokasi di Kabupaten Bolaang Mongondow Timur pada tiga kecamatan yaitu Kecamatan Kotabunan, Kecamatan Mooat dan Kecamatan Modayag. Dengan mempertimbangkan ketiga kecamatan adalah sasaran untuk menumbuh kembangkan Usaha dalam Pelayanan Jasa Alat Pertanian (UPJA) oleh Dinas Pertanian Kabupaten Bolaang Mongondow Timur.

\section{Metode Pengumpulan Data}

Metode pengumpulan data dalam penelitian ini menggunakan data primer dan sekunder. Data primer yaitu melalui wawancara secara langsung dengan menggunakan kuesioner serta melakukan pengamatan pada pihak -pihak yang terkait dalam sistem usaha pelayanan jasa alat mesin pertanian (UPJA). Sedangkan data sekunder yaitu data yang didapat melalui instansi yang terkait dalam penelitian ini.

\section{Metode Pengumpulan Sampel}

Metode pengambilan sampel secara garis besar terdiri atas: Sampling seadanya, Sampling pertimbangan atau purposif dan Sampling peluang. Penelitian ini merupakan jenis penelitian studi kasus, dimana sample yang akan diambil adalah sebagian unit usaha pelayanan jasa alat mesin pertanian (UPJA) di Kabupaten Bolaang Mongondow Timur yang mendapatkan atau menerima bantuan alat mesin pertanian dari pihak pemerintah. 


\section{Konsep Pengukuran Variabel}

Variabel-variabel yang di ukur dalam penelitian ini terdiri dari :

1. Unit usaha pelayanan jasa alat mesin pertanian (UPJA) dengan pertimbangan tertentu telah dipilih oleh peneliti.

2. Jumlah responden/sample untuk manager adalah 3 orang manager UPJA atas pertimbangan peneliti.

3. Sampel pengguna jasa, pada saat identifikasi yang pertama sejumlah 9 responden diambil 3 ketua kelompok tani pada tiap tiap kecamatan, dengan pertimbangan peneliti bahwa ketua kelompok tani mampu memberikan informasi yang dibutuhkan oleh peneliti dan dapat diajak komunikasi dengan baik.

4. Sample dari unsur penyedia alat mesin pertanian, terdiri pabrikan dan pengrajin / bengkel 3 orang.

5. Sample dari unsur subsistem permodalan dan pendanaan terdiri dari:

- Dinas Pertanian Kabupaten = 1 Orang

- Bank BRI = 1 Orang

6. Sample yang berasal dari subsistem pembinaan dan pengendalian, terdiri dari: Petugas Penyuluh Pertanian Lapangan (PPL) $=3$ orang, $($ masing - masing kecamatan 1 orang)

7. Sampel yang berasal dari pesaing usaha sejenis terdiri dari pesaing - pesaing yang mempunyai jenis peralatan mesin pertanian yang sama dengan milik UPJA masing masing 1 (satu) orang tiap kecamatan.

\section{Metode Analisis Data}

Analisis data dalam penelitian ini menggunakan metode analis SWOT yaitu melalui matriks yang digunakam dalam penyusunan faktor-faktor strategis lembaga usaha. Analisis SWOT ini dilakukan pada strategi meningkatkan daya saing pada usaha Jasa Alat dan Mesin Pertanian di Kabupaten Bolaang Mongondow Timur, hal ini disebut pula analisis situasi dengan model analisis SWOT.

Analisa ini berdasar pada logika untuk dapat mengembangkan sebesar-besarnya kekuatan (strength) serta peluang (opportunity), tetapi secara bersamaan juga bisa meminimalisir kelemahan (weakness) serta ancaman (threat).
Strength, weakness, opportunity and threat adalah empat faktor strategis lembaga usaha yang perlu dianalisa dalam keadaan pada saat ini. Rencan yang lebih populer untuk analisa situasi yakni analisa SWOT serta menggunakan Matrik Internal Factor Analysis Summary dan Matrik Eksternal Factor Analysis Summary.

\section{HASIL DAN PEMBAHASAN}

\section{Keadaan Umum Wilayah Penelitian}

Kabupaten Bolaang Mongondow Timur merupakan salah satu Kabupaten pemekaran dari Kabupaten Bolaang Mongondow, yang pembentukannya diatur dengan Undang Undang Nomor 29 Tahun 2008 Tentang Pembentukan Kabupaten Bolaang Mongondow Timur di Provinsi Sulawesi Utara. Luas wilayah Kabupaten Bolaang Mongondow Timur \pm 910,176 km2 terdiri dari 80 Desa, tersebar di 7 Kecamatan yakni Kecamatan Kotabunan, Kecamatan Tutuyan, Kecamatan Nuangan, Kecamatan Motongkad, Kecamatan Modayag, Kecamatan Mooat dan Kecamatan Modayag Barat.

Secara geografis Kabupaten Bolaang Mongondow Timur terletak pada 0035 ' 05' ' 00 57' 40" LU dan 1240 19' 09' - 1240 42' 16", BT. Batas - batas wilayah administrasi Kabupaten Bolaang Mongondow Timur adalah sebagai berikut:

- Sebelah Utara: Berbatasan dengan Kecamatan Touluaan, Kecamatan Tombatu, Kecamatan Ratatotok, Kabupaten Minahasa Tenggara.

- Sebelah Selatan: Berbatasan dengan Laut Maluku.

- Sebelah Barat : Berbatasan dengan Kecamatan Lolayan, Kecamatan Passi Timur, Kabupaten Bolaang Mongondow, Kecamatan Kotamobagu Timur, Kota Kotamobagu.

- Sebelah Timur : Berbatasan dengan Laut Maluku dan Kecamatan Pinolosian Kabupaten Bolaang Mongondow Selatan. 


\section{Sejarah Usaha Pelayanan Jasa alsintan (UPJA) di Kabupaten Bolaang Mongondow Timur}

Usaha Pelayanan Jasa alsintan (UPJA) adalah lembaga ekonomi di perdesaan dan bergerak di bidang pelayanan jasa dalam optimalisasi penggunaan alsintan untuk memperoleh keuntungan ekonomi usaha dari Poktan/Gapoktan. UPJA telah dibentuk tahun 2018 dengan modal awal diberikan bantuan oleh pemerintah berupa alsintan melalui program Kemeterian Pertanian melalui Direktorat Sarana dan Prasarana Pertanian guna untuk mendorong ekonomi pedesaaan yang bergerak di bidang penggunaan alat dan mesin pertanian dan pendorong menuju pertanian modern. Keadaan waktu itu untuk pemberian bantuan traktor roda dua (Hand Tractor), alat perontok multi guna (Power Thraser), mesin perontok jagung (corn Sheller), pompa air dan alat tanam jagung kepada 3 kelompok tani yang kemudian membentuk kelompok UPJA.

Secara operasional, Dinas Pertanian dan Peternakan Provinsi Sulawesi Utara mengawali program dengan melakukan sosialisasi misi program ke instansi dibawahnya, dalam hal ini adalah Dinas Pertanian Kabupaten Bolaang Mongondow Timur. Selanjutnya Dinas Pertanian Kabupaten Bolaang Mongondow Timur memilih lokasi yang diusulkan untuk menerima UPJA berdasarkan kriteria yang telah ditetapkan. Pada dasarnya kelompok tani terpilih ikut menentukan jumlah dan jenis alsintan yang dibutuhkan di wilayahnya, namun seringkali terjadi perubahan dengan alasan ketersediaan jenis alat dan anggaran yang terbatas. Hal ini mendasari jauhnya realita dari konsep pembentukan UPJA profesional seperti yang tercantum dalam Pedoman Umum Pengembangan UPJA (Ditjen alat dan mesin, 2012). Program UPJA bukan merupakan bantuan penuh kepada petani, melainkan stimulan usaha dari pemerintah.

\section{Pembentukan UPJA}

Penumbuhan UPJA dilaksanakan pada wilayah kawasan, agribisnis atau wilayah pengembangan kawasan agribisnis yang belum terbentuk UPJA, mempunyai masalah keterbatasan tenaga kerja dari penanganan hasil panen serta membutuhkan alsintan sebagai solusinya. Penumbuhan UPJA diinisiasi melalui musyawarah kelompok tani/Gapoktan dengan tokoh masyarakat serta petugas pertanian. Pembentukannya harus memenuhi syarat - syarat sebagai berikut :
- Mempunyai AD/ART

- Ada pertemuan rutin

- Menguasai/mempunyai keahlian tentang alsintan

- Mempunyai gudang penyimpanan alsintan

- Bermitra dengan bengkel alsintan

- Mempunyai Struktur Pengurus

\section{Tugas Pengurus UPJA}

- Tugas Manejer

- Menyusun rencana kerja usaha UPJA

- Mengendalikan dan mengawasi kerja operator dalam mengoperasikan Alsintran

- Memungut hasil operasional, mengeluarkan biaya operasional, biaya pemeliharaan , upah operator dan gaji pengurus.

- Memilih dan menunjuk operator yang memenuhi syarat dan bekerja sama dengan manejernan.

- Tugas Sekretaris

- Menyusun dan membuat buku daftar penyewaan Alsintan

- Menyusun jadwal dan lokasi opersional Alsintan

- Membuat laporan dan daftar sewa Alsintan

- Tugas Bendahara

- Menyusun dan membuat rencana pengeluaran

- Menyusun dan membuat rencana penerimaan

- Membuat laporan dan daftar penerimaan

- Membuat laporan dan daftar penngeluaran

- Membuat neraca keuangan

- Tugas Operator

- Menjalankan Alsintan untuk melayani permintaan petani pelanggan

- Melakukan pengamanan Alsintan dengan menyimpan setelah beroperasi

- Melakukan pencatatan mengenai kegiatan operasional Alsintan

- Melaporkan pelaksanaan kegiatan operasional kepada manejer.

\section{Analisis Strategi Pengembangan Usaha}

Pelayanan Jasa Alat dan Mesin Pertanian (UPJA) Kabupaten Bolaang Mongondow Timur

Hasil penelitian terhadap analisis strategi pengembangan UPJA di Kabupaten Bolaang Mongondow Timur berdasarkan faktor - faktor internal dan eksternal dalam pengembangan UPJA serta formulasi strategi pengelolaan untuk pengembangan UPJA yaitu penggalian dari sumber informasi yaitu pengelola usaha 
pelayanan jasa alat pertanian dengan menggunakan analisa SWOT. Diperoleh dengan dilakukannya ekplorasi dan klarifikasi kenyataan sosial atau penelitian survey sebagai berikut:

\section{Wawancara (interview)}

Terkait dengan Usaha Pelayanan Jasa Alat dan Mesin Pertanian (UPJA)

- Berdasarkan hasil wawancara dengan Manajer UPJA Bersama Kita Maju, Puncak Mooat dan Suka Maju tentang bagaimana sistem organisasi UPJA?

Menurut Manajer UPJA Bersama Kita Maju bahwa sistem organisasi berjalan dengan baik hanya ada terjadi pergantian operator satu orang dikarenakan operator tersebut sibuk pergi lokasi pertambangan dan untuk lainnya masih berjalan dengan baik.

Menurut Manajer UPJA Puncak Mooat bahwa sistem organisasi sekarang masih berjalan dengan baik artinya belum ada kendala dalam kepengurusan UPJA.

Hal yang serupa dengan Manajer UPJA Suka Maju kecamatan Modayag bahwa dalam organisasi banyak terjadi perubahan pengurus dan operator dikarenakan kurangnya disiplin anggota.

- Berdasarkan hasil wawancara dengan Manajer UPJA Bersama Kita Maju, Puncak Mooat dan Suka Maju tentang apa kendala dalam menjalankan bisnis UPJA?

Menurut manajer UPJA Bersama Kita Maju kendala dalam menjalankan bisnis ini adalah belum memadainya sarana prasarana dalam mendistribusi alsintan di lokasi pengguna, dalam hal ini adalah akses jalan sehingga sedikit terhambat bagi pengguna alsintan.

Bagi manajer Puncak Mooat bapak AM kendalanya adalah untuk service traktor roda empat karena di bengkel mitra UPJA masih kurangnya suku cadang sehingga untuk service sering mendatangkan pihak dari yanmar (pemilik merk TR4).

Dari UPJA Suka Maju bapak HM kendala utama adalah disiplin pengurus UPJA sehingga UPJA kurang berjalan dengan baik hal ini juga menyebabkan beberapa alsintan banyak terparkir di gudang. Terkait dengan wawancara Analisis lingkungan internal UPJA.
- Berdasarkan hasil wawancara dengan Manajer UPJA Bersama Kita Maju, Puncak Mooat dan Suka Maju tentang kemampuan manajer dalam mengelola UPJA? jawaban dari Para Manajer semuanya sama yakni :

Dalam mengelola UPJA manajer masih sangat mampu dan khusus untuk UPJA Suka Maju bapak AM menjelaskan bahwa akan melakukan revitaslisasi pengurus yang kurang disiplin guna untuk keberlanjutan UPJA mereka.

- Berdasarkan hasil wawancara dengan Manajer UPJA Bersama Kita Maju, Puncak Mooat dan Suka Maju tentang berapa jumlah tenaga kerja yang digunakan UPJA?

Menurut manajer UPJA Bersama Kita Maju Bapak. IP jumlah tenaga kerja UPJA hanya menggunakan 3 (tiga) Operator yaitu 2 (dua) operator hand traktor dan 1 (satu) operator CS dan PS.

Dari manajer UPJA Puncak Mooat bapak AM menggunakan 3 (tiga) Operator yaitu 1 (satu) orang untuk traktor roda empat, 1 (satu) operator traktor roda dua, dan 1 (satu) operator untuk cultivator dan pompa air.

Menurut manajer UPJA Suka Maju bapak HM jumlah tenaga kerja 1 orang operator karena alsintan hanya traktor roda dua.

- Berdasarkan hasil wawancara dengan Manajer UPJA Bersama Kita Maju, Puncak Mooat dan Suka Maju tentang Bagaimana tingkat keterampilan dan produktivitas Operator yang ada saat ini?

Jawaban dari para manajer semua sama yakni semua operator terampil dan produktif karena sering mengikuti pelatihan yang diadakan oleh Dinas Pertanian Kabupaten Bolaang Mongondow Timur.

- Berdasarkan hasil wawancara dengan Manajer UPJA Bersama Kita Maju, Puncak Mooat dan Suka Maju mengenai Apakah UPJA sudah mempunyai modal yang cukup selama menjalankan bisnis?

Manajer UPJA Bersama Kita Maju bapak IP menjawab cukup lumayan karena bisa menambah armada alsintan rontok padi (power tresher) 1 unit dan masih mempunyai simpanan sebesar Rp. 15. 000.000,- di kas UPJA. 
Jawaban dari manajer Puncak Mooat bapak AM hampir sama karena bisa menambah mesin cetak batako sehingga dapat memperlebar usaha tambahan, serta masih mempunyai saldo kurang lebih Rp. 10.000.000,-

Sedikit berbeda dengan jawaban dari manajer UPJA Suka Maju bapak HM keuntungan dari hasil sewa alat hanya untuk biaya service alat dan posisi kas saat ini masih minim, alsintan yang disewakan saat ini hanya 1 unit yang aktif, 3 lainnya masih butuh perbaikan lagi.

- Berdasarkan hasil wawancara dengan Manajer UPJA Bersama Kita Maju, Puncak Mooat dan Suka Maju mengenai Apa saja jenis alsintan yang digunakan, dan berapa jumlah rata-rata yang dihasilkan dalam 1 kali operasional?

Bapak IP dari UPJA Bersama Kita Maju terdapat 3 alsintan yang paling sering digunakan yaitu traktor roda 2 (dua) bisa 1 $\mathrm{Ha} /$ hari untuk hasil pembajakan sawah tapi tergantung cuaca misalnya hujan bisa lebih dari itu. Kemudian mesin rontok padi 1 ton/hari dan mesin rontok jagung $3 \mathrm{~s} / \mathrm{d} 4$ ton/hari.

Menurut manajer UPJA Puncak Mooat bapak AM mengatakan bahwa alsintan yang paling banyak beroperasional adalah traktor roda empat dan dapat menghasilkan setengah hari/ha sampai 1 hari/ha tergantung kemiringan lereng lahan yang dibajak.

UPJA Suka Maju bapak HM menjawab bahwa kebetulan hanya terdapat alsintan traktor roda 2 maka alat yang paling sering digunakan adalah traktor roda dua ini dan dapat menghasilkan 1 ha/hari.

- Berdasarkan hasil wawancara dengan Manajer UPJA Bersama Kita Maju, Puncak Mooat dan Suka Maju mengenai berapa harga sewa yang ditetapkan untuk masing - masing alsintan?

Jawaban dari para manajer UPJA mengatakan bahwa disetiap wilayah berbeda beda harga sewa tapi tetap mangacu pada aturan yang di tetapkan dalam ADRT UPJA dan yang pasti masih jauh dibawah para kompetitor di wilayah masing - masing UPJA.

- Berdasarkan hasil wawancara dengan Manajer UPJA Bersama Kita Maju, Puncak Mooat dan Suka Maju tentang bagaimana loyalitas konsumen UPJA?

Semua manajer UPJA menjawab bahwa loyalitas pengguna alsinta di UPJA masih sangat tinggi dan tidak perlu diragukan lagi.
- Berdasarkan hasil wawancara dengan ketua kelompok tani Bobakan kecamatan Kotabunan bapak A.R mengenai bagaimana perbedaaan pendapatan hasil produksi sebelum dan sesudah menggunakan alsintan?

Bapak A.R menjawab bahwa sebelum menggunakan alsintan untuk penggarapan lahan sawah miliknya biaya yang dikeluarkan untuk pola tradisional dengan menggunakan tenaga manusia dan hewan lebih banyak dan memakan waktu berhari - hari, sedangkan setelah menggunakan alsinta dalam hal ini traktor roda dua dengan biaya sewa yang masih bisa dijangkau serta proses penggarapan tidak memakan waktu yang lama, paling lama dua hari per hektar. Sehingga dapat menekan ongkos produksi serta meningkatkan pendapatan.

- Berdasarkan hasil wawancara dengan ketua kelompok tani Bulawan kecamatan Modayag bapak M.P mengenai bagaimana perbedaaan pendapatan hasil produksi sebelum dan sesudah menggunakan alsintan?

Bapak M.P menjawab bahwa dari segi pengolahan lahan sawah miliknya tidak memakan waktu yang lama serta pada proses panen dapat meningkatkan hasil dengan menggunakan perontok padi (Power Threser) karena efisien dalam menekan kehilangan hasil (kerusakan fisik gabah).

- Berdasarkan hasil wawancara dengan Manajer UPJA Bersama Kita Maju, Puncak Mooat dan Suka Maju tentang Siapa saja pengguna alsintan UPJA?

Semua manajer menjawab sama yaitu para kelompok - kelompok tani, para petani penggarap dan pengguna lain yang belum terdapat di kelompok tani.

- Berdasarkan hasil wawancara dengan Manajer UPJA Bersama Kita Maju, Puncak Mooat dan Suka Maju tentang Dari mana saja sumber modal yang digunakan UPJA?

Para manajer UPJA menjawab sumber modal UPJA semuanya berasal dari harga sewa alsintan dan modal awal yang dimiliki oleh UPJA itu sendiri.

- Berdasarkan hasil wawancara dengan Manajer UPJA Bersama Kita Maju, Puncak Mooat dan Suka Maju tentang Bagaimana sistem administrasi dan pembukuan UPJA?

Disini juga semua manajer UPJA menjawab sama yaitu sistem administrasi dan pembukuan UPJA sudah sesuai dengan prosedur dalam ADRT UPJA. 
- Berdasarkan hasil wawancara dengan Manajer UPJA Bersama Kita Maju, Puncak Mooat dan Suka Maju tentang Bagaimana UPJA mengelola keuangan?

UPJA Bersama Kita Maju bapak IP menjawab bahwa UPJA mengelola keuangan dengan baik sehingga sampai saat ini UPJA ketambahan alsintan dan Modal kas UPJA.

Terkait dengan wawancara Analisis lingkungan eksternal UPJA

- Berdasarkan hasil wawancara dengan Manajer UPJA Bersama Kita Maju, Puncak Mooat dan Suka Maju tentang Bagaimana stabilitas politik dan keamanan yang ada di Indonesia mempengaruhi usaha yang dijalankan UPJA dan Adakah kebijakan yang mempengaruhi usaha pelayanan jasa alsintan di UPJA secara langsung maupun tidak langsung?

Jawaban dari masing - masing manajer UPJA adalah dalam situasi pandemi Covid-19 saat ini memang sedikit berpengaruh dengan penggunaan alsintan karena harga dan pemasaran hasil bumi masih sedikit menurun, tapi dengan adanya new normal maka pelan - pelan mulai berkembang lagi.

- Berdasarkan hasil wawancara dengan Manajer UPJA Bersama Kita Maju, Puncak Mooat dan Suka Maju tentang Bagaimana prospek dan potensi pelayanan jasa alsintan ditinjau dari segi permintaan?

Jawaban dari masing - masing manajer UPJA adalah dari segi prospek dan permintaan masing normal seperti biasa belum terjadi peningkatan yang optimal karena pengguna alsintan masih sama.

- Berdasarkan hasil wawancara dengan kelompokkelompok tani pengguna alat serta kompetitor dan pihak terkait mengenai Apa dampak perubahan harga dan biaya operasional pada usaha pelayanan jasa alsintan UPJA?

Semua mengatakan sama yaitu tidak ada perubahan harga dan biaya operasional terkait keadaan sekarang ini, karena harga dan biaya masih sama seperti biasa.

- Berdasarkan hasil wawancara dengan kelompok - kelompok tani tentang Bagaimana tanggapan atas bisnis yang dijalankan UPJA?

Hampir semua mengatakan sangat membantu dalam pengolahan lahan serta harga sewa yang masih dapat dijangkau dibandingkan di tempat penyewaan alsintan lain.

- Berdasarkan hasil wawancara dengan kelompok - kelompok tani tentang Apa kontribusi yang diberikan UPJA terhadap lingkungan dan masyarakat sekitar?
Sejauh ini belum ada kontribusi diberikan UPJA terhadap lingkungan dan masyarakat sekitar selain kontribusi harga sewa yang murah. - Berdasarkan hasil wawancara dengan Manajer UPJA Bersama Kita Maju, Puncak Mooat dan Suka Maju tentang Bagaimana teknologi mempengaruhi kegiatan usaha UPJA?

Semua manajer menjawab bahwa teknologi yang sekarang ada di UPJA sudah sangat membantu dengan keadaan lahan masyarakat saat ini, tapi menurut manajer UPJA Bersama Kita Maju bahwa dari segi teknologi di wilayah kecamatan Kotabunan sudah sangat sesuai tapi mereka berencana membeli alsintan traktor roda dua otomatis pakai remot kontrol dengan mengumpulkan modal UPJA, jika belum ada bantuan yang di usulkan melalui proposal kepada Pemerintah Daerah melalui Dinas Pertanian Kabupaten Bolaang Mongondow Timur.

Berdasarkan wawancara maka dilihat dari segi penerapan penggunaan alat dan mesin pertanian diharapkan dapat memecahkan masalah kekurangan tenaga kerja baik saat pengolahan, panen maupun pascapanen, menekan ongkos produksi, menekan kehilangan hasil serta meningkatkan produksi dan pendapatan petani.

Secara umum peneliti menyimpulkan bahwa dalam menyangkut organisasi UPJA, Analisis Internal dan Eksternal Usaha Pelayanan Jasa Alat dan Mesin Pertanian di Kabupaten Bolaang Mongondow Timur secara umum dari sisi organisasi berjalan dengan baik, faktor internal dan eksternal masih terkontrol dengan baik dan kendala masih bisa diatasi oleh pengurus UPJA.

\section{Analisis Faktor Internal \& Eksternal}

\section{Analisis Faktor Internal}

Analisa faktor internal adalah kegiatan analisa pada kekuatan serta kelemahan dalam perkemabngan UPJA. Analisa ini merupakan sebagian dari usaha yang menjadi sumberdaya bisnis UPJA dan bisa menjadi kekuatan bila dikelola secara efektif dan efisien, tetapi sebaliknya jika dikelola secara buruk maka akan menjadi suatu kelemahan UPJA. Hasil rating rata rata analisa terhadap lingkungan faktor internal dapat dilihat pada Tabel 1 . 
Tabel 1. Matrik Analisis Strategi Faktor Internal (IFAS) Pengembangan UPJA Di Kabupaten Bolaang Mongondow Timur

\begin{tabular}{cccc}
\hline $\begin{array}{c}\text { IFAS } \\
\text { KEKUATAN }\end{array}$ & $\begin{array}{c}\text { Bobot } \\
\text { (rata-rata) }\end{array}$ & $\begin{array}{c}\text { Rating } \\
\text { (rata-rata) }\end{array}$ & $\begin{array}{c}\text { Skor } \\
\text { (rata-rata) }\end{array}$ \\
\hline Kemampuan Manajerial & 0.12 & 3.50 & 0.42 \\
Jumlah Operator & 0.09 & 3.11 & 0.28 \\
Kemampuan Operator & 0.13 & 3.67 & 0.48 \\
Modal Investasi UPJA & 0.10 & 3.33 & 0.33 \\
Kualitas/Teknologi Alsintan & 0.11 & 3.39 & 0.37 \\
\hline \multicolumn{1}{c}{ Sub Total } & 0.55 & & 1.88 \\
\hline IFAS & Bobot & Rating & Skor \\
\multicolumn{1}{c}{ KELEMAHAN } & (rata-rata) & (rata-rata) & (rata-rata) \\
\hline Alsintan Terbatas & 0.09 & 1.33 & 0.12 \\
Pelayanan Pada Konsumen & 0.11 & 1.94 & 0.21 \\
Koordinasi Instansi Terkait & 0.10 & 1.72 & 0.17 \\
Disiplin Pengurus UPJA & 0.08 & 1.22 & 0.10 \\
Sosialisasi Kurang & 0.07 & 1.11 & 0.08 \\
\hline Sub Total & 0.45 & & 0.68 \\
\hline Total Faktor Internal & 1.00 & & 2.56 \\
\hline
\end{tabular}

Sumber : Data Primer, diolah

Tabel 1 menunjukkan bahwa skor paling tinggi dalam faktor internal untuk bagian kekuatan yaitu kemampuan Operator (0.48) dan Kemampuan Manajerial (0.42). sedangkan pada sisi kelemahan skor terendah terdapat pada kurangnya sosialisasi (0.08). Hal ini dikarenakan faktor pengalaman operator alat dan mesin pertanian serta kemampuan manajerial adalah faktor utama keberhasilan usaha pelayanan jasa alsin (UPJA). Operator alsintan dan Manajer handal UPJA adalah satu kesatuan yang tidak dapat dipisahkan dalam mengorganisasi UPJA hingga bisa mengelola lembaga menjadi semakin maju dan berkembang sebagaimana tugas dan fungsi masing - masing pengurus, serta mampu menyesuaikan dengan peluang bersama petani sebagai pengguna jasa baik yang ada disekitar wilayah kerja ataupun di luar. Faktor sosialisasi adalah faktor kelemahan yang perlu mendapat perhatian apabila arah perkembangan UPJA menuju secara usaha profesional terwujud. Pada prinsipnya dalam melakukan sosialisasi adalah dengan melakukan pendekatan kepada para pengguna jasa dan melakukan promosi baik turun ke wilayah atau lahan petani serta mempromosikan biaya yang bisa dijangkau oleh pengguna jasa maupun sosialisasi lainnya yakni bekerjasama dengan petugas penyuluh pertanian lapangan sehingga UPJA tersebut dapat dikenal luas oleh petani pengguna jasa.

\section{Analisis Faktor Eksternal}

Faktor analisis eksternal adalah kegiatan menganalisa pada sisi peluang (Opportunity) serta ancaman (Threat) pengembangan dalam UPJA. Analisa ini merupakan faktor pendukung untuk perkembangan bisnis UPJA dan bisa menjadi peluang apabila dimanfaatkan dengan baik dan efektif, begitu juga jika tidak dimanfaatkan dengan efektif akan berubah menjadi ancaman kepada Usaha Pelayanan Alat Pertanian tersebut. Matriks analisis strategi faktor eksternal (EFAS) dapat dilihat pada Tabel 2.

Tabel 2. Matrik Analisis Strategi Faktor Eksternal (EFAS) Pengembangan UPJA di Kabupaten Bolaang Mongondow Timur

\begin{tabular}{|c|c|c|c|}
\hline $\begin{array}{c}\text { EFAS } \\
\text { PELUANG }\end{array}$ & $\begin{array}{c}\text { Bobot } \\
\text { (rata-rata) }\end{array}$ & $\begin{array}{l}\text { Rating } \\
\text { (rata-rata) }\end{array}$ & $\begin{array}{c}\text { Skor } \\
\text { (rata-rata) }\end{array}$ \\
\hline $\begin{array}{l}\text { Dukungan dan Bantuan } \\
\text { Pemerintah }\end{array}$ & 0.11 & 3.50 & 0.39 \\
\hline $\begin{array}{l}\text { Tersedia Pinjaman } \\
\text { UMKM/BANK }\end{array}$ & 0.11 & 3.50 & 0.39 \\
\hline Suku Cadang Alsintan & 0.09 & 2.94 & 0.27 \\
\hline Harga Sewa Alsintan & 0.12 & 3.72 & 0.45 \\
\hline Keuntungan Ekonomis & 0.10 & 3.39 & 0.34 \\
\hline Sub Total & 0.53 & & 1.82 \\
\hline $\begin{array}{c}\text { EFAS } \\
\text { ANCAMAN }\end{array}$ & $\begin{array}{c}\text { Bobot } \\
\text { (rata-rata) }\end{array}$ & $\begin{array}{c}\text { Rating } \\
\text { (rata-rata) }\end{array}$ & $\begin{array}{c}\text { Skor } \\
\text { (rata-rata) }\end{array}$ \\
\hline Kompetitor UPJA & 0.11 & 2.89 & 0.32 \\
\hline $\begin{array}{l}\text { Kurangnya Sarana } \\
\text { Infrastruktur }\end{array}$ & 0.10 & 2.39 & 0.24 \\
\hline $\begin{array}{l}\text { Kuatnya Hubungan Sosial } \\
\text { Petani }\end{array}$ & 0.10 & 2.39 & 0.24 \\
\hline $\begin{array}{l}\text { Tingkat Pengetahuan } \\
\text { Rendah }\end{array}$ & 0.07 & 1.78 & 0.12 \\
\hline Modal Petani Rendah & 0.09 & 2.11 & 0.19 \\
\hline Sub Total & 0.47 & & 1.11 \\
\hline Total Faktor Eksternal & 1.00 & & 2.93 \\
\hline
\end{tabular}

Sumber : Data Primer, diolah

Tabel 2 menunjukkan bahwa jumlah rata rata rating di atas maka faktor eksternal punya nilai rating yang paling tinggi pada sisi peluang dari UPJA yaitu pada harga sewa alat dan mesin pertanian yang masih relatif terjangkau. Pada sisi ancaman, faktor yang perlu harus diperhatikan dari UPJA yakni pada tingkat pengetahuan petani terhadap alat yang masih minim.

\section{Menyusun Strategi Perkembangan Usaha Pelayanan Jasa Alat Pertanian Kabupaten Bolaang Mongondow Timur}

Matrik dari SWOT adalah gabungan faktorfaktor dari strategi internal dan eksternal hingga dapat menghasilkan strategi operasional dalam mencapai tujuan pengembangan Usaha Pelayanan Alsintan atau UPJA. Dengan melihat matrik bobot dan stategi diatas, maka ditentukan kombinasi strategi yang bisa dilakukan dalam pengembangan Usaha Pelayanan Jasa Alat Pertanian Kabupaten Bolaang Mongondow Timur. Dapat dilakukan persilangan antara faktor - faktor tersebut di atas maka akan diperoleh suatu strategi yang dapat menjadi acuan dalam pengembangan UPJA di Kabupaten Bolaang Mongondow Timur yang dapat dilihat pada Tabel 3. 
Tabel 3. Matriks SWOT Pengembangan UPJA di Kabupaten Bolaang Mongondow Timur

\begin{tabular}{|c|c|c|}
\hline EFAS & $\begin{array}{l}\text { KEKUATAN (Strength) } \\
\text { Kemampuan Manajerial } \\
\text { Jumlah Operator } \\
\text { Kemampuan operator } \\
\text { Modal Investasi UPJA } \\
\text { Teknologi Alsintan }\end{array}$ & $\begin{array}{l}\quad \text { KELEMAHAN (Weakness) } \\
\text { Alsintan tersedia terbatas } \\
\text { Pelayanan pada Konsumen } \\
\text { Koordinasi dengan Dinas terkait } \\
\text { Disiplin dari anggota UPJA } \\
\text { Sosialisasi masih kurang }\end{array}$ \\
\hline PELUANG (Opportunity) & STRATEGI S - O & STRATEGI W - O \\
\hline $\begin{array}{l}\text { - Dukungan dengan mendapat } \\
\text { Bantuan dari Pemerintah } \\
\text { - Tersedia pinjaman bank } \\
\text { - Suku cadang alsintan } \\
\text { - Harga Sewa Alsintan } \\
\text { - Keuntungan ekonomis }\end{array}$ & $\begin{array}{l}\text { Melakukan sosialisasi atas } \\
\text { dukungan Dinas terkait } \\
\text { (S1O1) } \\
\text { - Menjalin hubungan atau } \\
\text { bermitra dengan Bank } \\
\text { (S1O2) } \\
\text { - Peningktan Peluang usaha } \\
\text { pertanian baru (S4O5) } \\
\text { - Peningkatan ketersediaan alat } \\
\text { pertanian (S4O3) }\end{array}$ & $\begin{array}{l}\text { - Sosialisasi penggunaan alsintan } \\
\text { dengan dukungan Pemerintah } \\
\text { (W5O1) } \\
\text { - Memperbanyak alsintan dengan } \\
\text { menajalin kerjasama dengan } \\
\text { pihak BANK (W1O2) } \\
\text { - Mengembangkan dan } \\
\text { meningkatkan kerjasama dengan } \\
\text { anggota untuk keberlanjutan } \\
\text { UPJA (W4O5 }\end{array}$ \\
\hline
\end{tabular}

\begin{tabular}{lll}
\hline \multicolumn{1}{c}{ ANCAMAN (Threat) } & \multicolumn{1}{c}{ STRATEGI S - T } & \multicolumn{1}{c}{ STRATEGI W - T } \\
\hline - Kompetitor bisnis UPJA & - Bantuan Modal Untuk & - Membentuk Poktan serta \\
- Kurangnya Sarana & Pengembangan Usaha (S4T5) & memberikan bantuan pelayanan \\
Infrastruktur & - Pembangunan infrastruktur & secara kolektif serta menjalin \\
- Hubungan sosial yang kuat & pertanian (S4O3) & hubungan yang baik dengan \\
antar petani & - Memberikan pengetahuan & kompetitor (W1T1,3) \\
- Pengetahuan teknologi yg & kepada petani pengguna & - Memksimalkan Usaha dalam \\
rendah & alsintan (S3O4) & penggunaan alat pertanian oleh \\
- Modal petani yang masih & - Membangun kerjasama yang & poktan (W1T4,5) \\
rendah & erat dengan pungguna alsintan & \\
& (S1O1) & \\
& &
\end{tabular}

\section{Strategi Kekuatan dan Peluang (Strength Opportunity/ S-O)}

Strategi S O adalah strategi dimana dapat memaksimalkan sumber kekuatan UPJA dalam pemanfaatan peluang. berikut ini ada empat stategi yakni

1. Melakukan sosialisasi atas dukungan pihak pemerintah dalam hal ini instansi terkait Dinas Pertanian dengan pemanfaatan faktor kekuatan kemampuan dalam manajerial pengelola Usaha Pelayanan Jasa Alat Pertanian karena mempunyai peluang dukungan yang baik dari Dinas Pertanian selaku Pemerintah Daerah untuk pertumbuhan dan perkembangan Usaha Pelayanan Jasa Alat Pertanian.

2. Pengembangan kerjasama dengan pihak BANK, dengan memanfaatkan kekuatan manajerial UPJA dalam menjalin kerjasama dalam hal pembiayaan terkait apa yang sangat di butuhkan oleh UPJA.
3. Peningkatan peluang usaha pertanian yang lain dengan pemanfaatan faktor kekuatan dimana terdapat modal investasi UPJA untuk memanfaatkan keuntungan secara ekonomis untuk kesejahteraan dan pengembangan UPJA.

4. Peningkatan ketersediaan alat pertanian dengan memanfaatkan peluang suku cadang alat pertanian yang terjamin dan mudah dijumpai karena sebagian UPJA memiliki bengkel serta mempunyai teknologi alat pertanian yang lebih ramah lingkungan.

\section{Strategi Kekuatan dan Ancaman (Strenght Threats / S-T)}

Strategi S T adalah strategi menggunakan kekuatan dalam menghadapi ancaman. strategi ini antara lain : 
1.Pemberian modal untuk menumbuh kembangkan usaha, yakni memanfaatkan sumber kekuatan dengan bantuan modal investasi dari UPJA karena melihat dari segi ancaman dimana modal yang dimiki petani masih rendah

2. Melakukan pembangunan infrastruktur pertanian dalam mengantisipasi kemajuan teknologi alat pertanian yang ramah lingkungan serta kemudahan dalam pengoperasiannya dan dari segi ancaman kurangnya prasarana dan sarana bidang pertanian, khususnya pembukaan atau rehabilitasi jalan usaha tani.

3. Menciptakan hubungan yang kuat dengan ketua - ketua kelompok tani selaku pengguna alat dan mesin pertanian, tujuanya adalah untuk meminimalisir penggunaan alsintan dari luar UPJA dalam hal ini kompetitor UPJA itu sendiri.

\section{Strategi Kelemahan dan Peluang (Weakness - Opportunity/WO)}

Strategi W O adalah strategi yang meminimalkan suatu kelemahan dalam pemanfaatan peluang. strategi ini antara lain adalah

1. Melaksanakan sosialisasi dalam penggunaan alat pertanian guna meningkatkan produktivitas, yakni dengan memanfatkan peluang yang ada serta dukungan dan bantuan Pemerintah dalam hal ini adalah penyuluhan kepada UPJA dan kelompok - kelompok tani dalam mengantisipasi kurangnya sosialisasi.

2. Menambah alat dan mesin pertanian dengan dukungan modal pinjaman dari Bank untuk menutupi keterbatasan alsintan yang dimiliki oleh UPJA.

3. Mengembangkan dan meningkatkan hubungan antara manajer dan anggota guna untuk mengatasi kurangnya disiplin dan kerjasama antar pengurus untuk keberlanjutan lembaga UPJA dan dari segi keuntungan ekonomis UPJA itu sendiri.

\section{Strategi Kelamahan dan Ancaman (Weakness Threats / W-T)}

Strategi W $T$ yaitu strategi yang meminimalkan suatu kelemahan dalam mengatasi ancaman. strategi ini antara lain adalah
1. Melaksanakan sosilisasi tentang pembentukan poktan/gapoktan serta pemberian bantuan dalam pelayanan secara menyeluruh, untuk bertujuan menanggulangi lemahnya proses administrasi dalam pelayanan kepada petani dan mengurangi penggunaan alsintan diluar UPJA.

2. Melaksanakan efisiensi usaha dalam penggunaan alat pertanian oleh petani untuk mengatasi hubungan sosial yang kuat antar petani serta kurangnya jenis alat pertanian.

Gabungan antara faktor dari lingkungan internal dan eksternal merupakan hal utama dalam memperoleh alternatif strategi yang efektif dan efisien. Tiap - tiap lembaga UPJA mempunyai peluang dan ancaman pada faktor eksternal serta kekuatan dan kelemahan internal yang bisa dipadupadankan dalam memformulasikan alternatif strategi yang terbaik dan layak.

Formulasi untuk strategi pengembangan Usaha Pelayanan Jasa Alat Pertanian Kabupaten Bolaang Mongondow Timur yaitu dapat menggunakan strategi agresif, dimana :

1. Melaksanakan sosialisasi dengan dukungan pemerintah daerah melalui dinas terkait

2. Menumbuh kembangkan kerjasama dengan petani

3. Peningkatan peluang usaha pertanian lain yang dimiliki UPJA

4. Peningkatan ketersediaan alat mesin pertanian

Alternatif atau pilihan lain dari strategi dalam pengembangan Usaha Pelayanan Jasa Alat Pertanian Kabupaten Bolaang Mongondow Timur tersebut lebih diarahkan kepada peran Dinas Pertanian selaku pihak Pemerintah Daerah setempat agar secara aktif dalam pembinaan serta mendorong dan mendukung usaha pengembangan Usaha Pelayanan Jasa Alat Pertanian dengan cara antara lain :

1. Melaksanakan Sosialisasi tentang konsep dasar dalam pengembangan Usaha Pelayanan Jasa Alat Pertanian untuk seluruh Pengurus UPJA

2. Melaksanakan penyuluhan, monitoring dan evaluasi serta pembinaan terkait program dalam penguatan Usaha Pelayanan Jasa Alat Pertanian oleh Dinas terkait yakni Dinas Pertanian. 
3. Membuat rangkaian konsep dan asas atau kebijakan regulasi yang terkait untuk mendukung permodalan serta penyempurnaan atau memperbarui infrastruktur guna kelancaran berjalannya kegiatan pengoperasian alat dan mesin pertanian.

\section{KESIMPULAN DAN SARAN}

\section{Kesimpulan}

1. Kajian faktor internal dan faktor eksternal dalam pengembangan usaha pelayanan jasa alat mesin pertanian atau UPJA yaitu :

a) Faktor internal yang menentukan pengembangan UPJA di Kabupaten Bolaang Mongondow Timur yaitu kemampuan dalam manajerial perusahaan serta pengalaman dari operator bisa disebut sebagai kekuatan dan juga administrasi perusahaan dalam pelayanan kepada petani.

b) Faktor pada eksternal perusahaan yang ikut dalam penentuan arah pengembangan usaha pelayanan jasa alat pertanian yaitu dukungan Pemerintah dalam hal ini Dinas Pertanian Kabupaten Bolaang Mongondow Timur dalam pemberian alsintan kepada UPJA dan potensi tersedianya pinjaman Bank yang sangat mendukung untuk pengembangan UPJA serta jaminan dan kemudahan suku cadang. kemudian dari faktor ancaman adalah faktor yang mendapat perhatian yaitu rendahnya pengetahuan petani serta modal petani untuk penggunaan alsintan.

2. Formulasi strategi pengembangan Usaha Pelayanan Jasa Alat Mesin Pertanian Kabupaten Bolaang Mongondow Timur yaitu strategi agresif atau pada kuadran I dimana strategi yang digunakan adalah semua kekuatan untuk memanfaatkan peluang yang ada, sebagai alternatif strategi :

a) Melaksanakan sosialisasi dengan dukungan pemerintah daerah melalui dinas terkait

b) Menumbuh kembangkan kerjasama dengan petani

c) Peningkatan peluang usaha pertanian lain yang dimiliki UPJA

d) Peningkatan ketersediaan alat mesin pertanian.

\section{Saran}

Upaya untuk mendukung strategi pengembangan Usaha Pelayanan Jasa Alat Pertanian atau UPJA Kabupaten Bolaang Mongondow Timur, hal-hal yang disarankan adalah

1. Peningkatan sosialisasi pada penggunaan alat pertanian untuk memperoleh produktivitas yang optimal.

2. Dipermudah prosedur untuk kepemilikan alat mesin pertanian

3. Diperlukan kerjasama dari Pemerintah Daerah untuk mendukung kemajuan pembangunan dibidang pertanian melalui kebijakan dalam meningkatkan produksi serta sistem dalam mendapatkan kredit usaha rakyat.

\section{DAFTAR PUSTAKA}

Badan Pusat Statistik Kota Kotamobagu. 2020. Kabupaten Bolaang Mongondow Timur Dalam Angka 2020. Sulawesi Utara.

Dinas Pertanian, 2019. Laporan Perkembangan Alat Dan Mesin Pertanian Tahun Anggaran 2019. Pemerintah Kabupaten Bolaang Mongondow Timur, Dinas Pertanian, Tutuyan.

Direktorat Alat dan Mesin Pertanian. 2011. Penguatan Usaha Pelayanan Jasa Alsin Pertanian (UPJA) Pemula, Berkembang dan Profesional. Pedoman Teknis. Ditjen Prasarana dan Sarana Pertanian. Kementerian Pertanian. Jakarta.

Direktorat Alat dan Mesin Pertanian. 2012. Operasional Pengembangan, Pengawasan, dan Kelembagaan Alat dan Mesin Pertanian. Pedoman Teknis. Ditjen Prasarana dan Sarana Pertanian. Kementerian Pertanian. Jakarta.

Ditjen Prasarana Dan Sarana Pertanian, 2008. Peraturan Menteri Pertanian Nomor 25/Permentan/Pl.130/5/2008, Pedoman Penumbuhan Dan Pengembangan Usaha Pelayanan Jasa Alat Dan Mesin Pertanian, Kementerian Pertanian Republik Indonesia. Jakarta. 
Ditjen Prasarana dan Sarana Pertanian, 2019. Kebijakan Pemanfaatan Alsintan Dalam Mendukung Peningkatan Produksi Pertanian Tahun Anggaran 2018. Kementerian Pertanian Republik Indonesia. Jakarta.

Ditjen Prasarana dan Sarana Pertanian, 2019. Layanan Sertifikasi Alat Dan Mesin Pertanian, Kementerian Pertanian Republik Indonesia. Jakarta.
Ditjen Tanaman Pangan. 2010. Pengembangan Pelayanan Usaha Jasa alat dan Mesin Pertanian (UPJA). Pedoman Pelaksanaan. Kementerian Pertanian. Jakarta. 